\title{
The Effects of Ambient Ions on the Growth of Gold Nanoparticles by Laser Ablation in Liquid ${ }^{\dagger}$
}

\author{
Hyejin Kwon, Kuk Ki Kim, Jae Kyu Song, and Seung Min Park* \\ Department of Chemistry, Kyung Hee University, Seoul 130-701, Korea. "E-mail: smpark@khu.ac.kr \\ Received September 30, 2013, Accepted October 2, 2013
}

\begin{abstract}
Gold nanoparticles (AuNPs) were synthesized by laser (Nd:YAG, $\lambda=1064 \mathrm{~nm}$ ) ablation of a gold target immersed in various aqueous electrolyte solutions ( $7 \mathrm{mM}$ of $\mathrm{LiCl}, \mathrm{NaCl}, \mathrm{KCl}, \mathrm{NaBr}$, and $\mathrm{NaI})$ as well as in deionized water. The surface plasmon absorption and EDX of AuNPs so produced as well as their TEM images were analyzed to investigate the effects of ambient ions on the growth and aggregation of NPs. The size of AuNPs was reduced by laser ablation in the presence of chloride and bromide ions while it increased drastically when AuNPs were formed in iodide solution. Interestingly, triangular nanoplates were synthesized only in iodide solution. Surface chemistry on AuNPs in various electrolyte solutions was explored to elucidate the role of ions on the size and stability of AuNPs.
\end{abstract}

Key Words : Gold nanoparticles, Liquid laser ablation, Size control, Halide ions

\section{Introduction}

Compared to bulk materials, nanoparticles (NPs) have peculiar optical, ${ }^{1}$ electrical, ${ }^{2}$ and magnetic properties $^{3}$ which allow novel applications in various fields including electronics, ${ }^{4}$ sensors, ${ }^{5,6}$ solar cells, ${ }^{7}$ functional textiles, ${ }^{8}$ and paints. ${ }^{9}$ Also, they are widely used in biomedical field such as medicine, ${ }^{10,11}$ imaging, ${ }^{12}$ and therapy. ${ }^{13}$

Among many, gold and silver metal NPs are indispensable for biomedical technologies due to their unique size- and shape-dependent optical properties ${ }^{14}$ as well as their low toxicity ${ }^{15-17}$ compared to others. In particular, their surface plasmon frequencies in visible region ${ }^{18,19}$ are certainly strong advantages over the others. Consequently, gold and silver NPs have been adopted as signal amplifiers in surface enhanced Raman spectroscopy (SERS) ${ }^{20-23}$ and, furthermore, they are recently spotlighted as promising platform materials for theranosis. ${ }^{24,25}$ For these applications, extensive research has been devoted to control the surface plasmon resonance (SPR) by manipulating the size and shape of NPs over the last two decades.

Generally, NPs are synthesized by chemical reduction, where their size and shape are controlled mainly by varying reducing agents and surfactants. ${ }^{26,27}$ However, this method requires extra purification process to get rid of residual chemicals on the surface, which are often responsible for toxicity. ${ }^{28}$ Recently, laser ablation in liquid (LAL) has been suggested to replace the chemical reduction as a highly convenient and environment-friendly method. ${ }^{29}$ In LAL, gold and silver NPs can be synthesized in a solvent without any chemicals such as surfactants, which are frequently added to prevent aggregation in chemical reduction..$^{20,22,23,30}$

Stabilizing nanoparticles to avoid aggregation has been

${ }^{T}$ This paper is to commemorate Professor Myung Soo Kim's honourable retirement. one of the most important issues in nanotechnology. In NPs, more atoms exist in the surface area compared to the bulk and their high surface energies are beneficial as catalysts. ${ }^{26}$ Since NPs aggregate easily and grow bigger, it is important to maintain their small sizes in this regard. In uncapped NP colloid, the Brownian motion of nanoparticles induces collision of two nanoparticles and they attract with each other eventually to form aggregates through the van der Waals interaction. ${ }^{31}$ To solve such aggregation problems, researchers attempted to form barriers between particles using polymer dispersing agents, ${ }^{32,33}$ surfactants, ${ }^{34-37}$ and surface modification, ${ }^{38,39}$ but using such additives and organic solvent ${ }^{40,41}$ to prevent aggregation and to control the morphology of NPs are far from the "green" nature of LAL. As well as organic agents, biocompatible salt such as $\mathrm{NaCl}$ can also be adopted to reduce the size of gold and silver NPs even in very low concentration. ${ }^{23,42-44}$

Here, we explored the effects of different types of salts dissolved in the liquid laser ablation medium on the morphology and size of gold nanoparticles (AuNPs). $\mathrm{NaCl}$, which has been known to have size quenching effect for gold and silver NPs in LAL, was adopted as a standard to examine the effects of ions; $\mathrm{LiCl}$ and $\mathrm{KCl}$ were selected to study the effects of cations and $\mathrm{NaBr}$ and $\mathrm{NaI}$ were chosen to investigate the role of anions.

\section{Experimental}

AuNPs solution was produced by laser ablation of a gold target $(99.99 \%)$ which was immersed in aqueous solution using a customized cell. Focused Nd:YAG laser (Continuum, Surelite III, $1064 \mathrm{~nm}, 10 \mathrm{~Hz}$ ) pulse was employed as an ablation light source. The diameter of the laser spot on the target surface was approximately $1.2 \mathrm{~mm}$ and the Au target was irradiated for $5 \mathrm{~min}$. All salts were purchased from Sigma-Aldrich and were dissolved in deionized water (18.2 
$\mathrm{M} \Omega$ ) to prepare electrolyte solutions.

We have prepared AuNPs solutions in two different methods. In the Method I, in order to study the effects of ambient ions during laser ablation, the Au target was placed in electrolyte solutions ( $7 \mathrm{mM}$ ) including salts such as $\mathrm{LiCl}$, $\mathrm{KCl}, \mathrm{NaCl}, \mathrm{NaBr}$, and $\mathrm{NaI}$. The Au target was ablated at 100 $\mathrm{mJ} /$ pulse and the volume of the solution was $15 \mathrm{ml}$. In the Method II, we made AuNPs solution by laser ablation of the $\mathrm{Au}$ target for $20 \mathrm{~min}$ in $10 \mathrm{~mL}$ deionized water and subsequently mixed it with electrolyte solution to investigate the effects of ions on the stability of NPs. The resultant concentration of salt was $7 \mathrm{mM}$ as in the case of the Method I.

UV-Vis spectra of NP colloids were obtained with a UVVis spectrometer (Shimadzu, UV-1800) in the range of 190$1000 \mathrm{~nm}$ using a $10 \mathrm{~mm}$ optical path quartz cell. Images of NPs were captured by field emission transmission electron microscopy (FE-TEM, FEI, Tecnai G2F30) at $300 \mathrm{kV}$ and energy filtering-transmission electron microscopy (EF-TEM, Carl Zeiss, Leo 912AB) at $120 \mathrm{kV}$. Zeta potentials of colloidal solutions were measured by electrophortic light scattering spectrophotometer (ELS, Otsuka Electronics, ELS-8000).

\section{Results}

Method I: Synthesis of Gold Nanoparticles in Electrolyte Solutions. Figure 1 shows the effects of ambient electrolytes on the properties of the surface plasmon band (SPB)
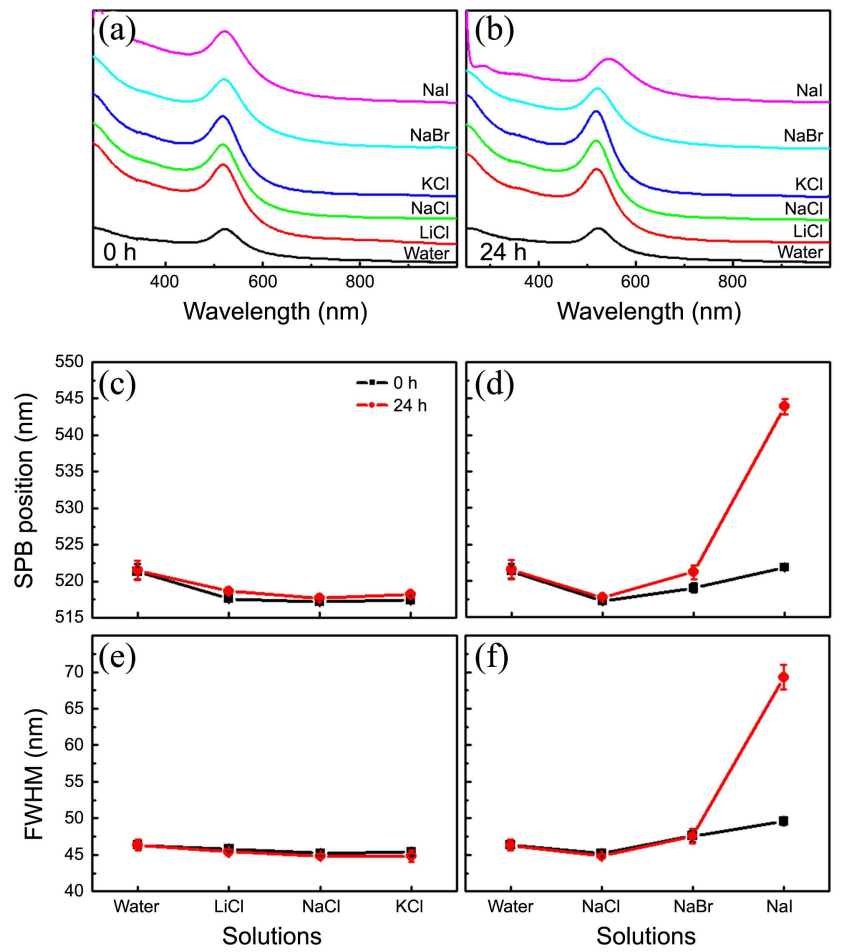

Figure 1. UV-Vis spectra of AuNPs synthesized by LAL in various electrolyte solutions (the Method I) (a) right after synthesis $(0 \mathrm{~h}),(\mathrm{b})$ after $24 \mathrm{~h}$; the shift of the surface plasmon band peak position for various electrolyte solutions (c) with different cations, (d) with different anions; the change in the FWHM for various electrolyte solutions (e) with different cations, (f) with different anions. of AuNPs solutions. For salt solutions with different cations ( $\mathrm{LiCl}, \mathrm{NaCl}, \mathrm{KCl}$ ), the SPB peak positions and FWHMs were nearly the same (Figs. 1(c) and 1(e)). On the contrary, the difference was noticeable for different types of anions and became more apparent after $24 \mathrm{~h}$ as shown in Figures 1(d) and 1(f). The SPB peak was blue shifted in the presence of chloride ions ( $\mathrm{LiCl}, \mathrm{NaCl}, \mathrm{KCl}$ ) compared to deionized water and it remained nearly the same after $24 \mathrm{~h}$. In $\mathrm{NaBr}$ solution, the SPB peak wavelength was placed between $\mathrm{NaCl}$ and deionzed water, and it shifted closer to deionized water after $24 \mathrm{~h}$. The spectral change before and after $24 \mathrm{~h}$ was dramatic for NaI solution; the peak was red shifted and the FWHM also increased in NaI compared to the deionized water case. The dramatic change in NaI solution after $24 \mathrm{~h}$ represents a poor stability of AuNPs colloid, and it is supported by the zeta potential measurements; the zeta potential values for NPs solutions produced in $\mathrm{NaCl}, \mathrm{NaBr}$, and $\mathrm{NaI}$ solutions were $-35.99 \pm 1.40 \mathrm{mV},-31.32 \pm 3.71 \mathrm{mV}$, and $-27.89 \pm 4.22 \mathrm{mV}$, respectively.

The red shift of SPB peak reflects the increase in the size of NPs, ${ }^{41,45}$ which can be also confirmed by TEM images in Figures 2(a)-(c). The average sizes of NPs in $\mathrm{NaCl}, \mathrm{NaBr}$, and $\mathrm{NaI}$ were $5.3 \pm 2.7 \mathrm{~nm}, 7.0 \pm 4.6 \mathrm{~nm}$, and $41.6 \pm 38.9$ $\mathrm{nm}$, respectively. In NaI, extremely big particles with diameters over $200 \mathrm{~nm}$ were also observed, and the shapes of the NPs were not only spherical but also triangular, and hexagonal. In particular, big triangular and hexagonal NPs with many small NPs attached on the surface were observed as shown in Figure 2(d). This structure was identified also by EDX and will be discussed later. Although some triangular and hexagonal nanoplates were found, their presence was not quite revealed in the UV-Vis spectrum as the second SPB in the infrared region presumably due to their low concentrations. ${ }^{46,47}$

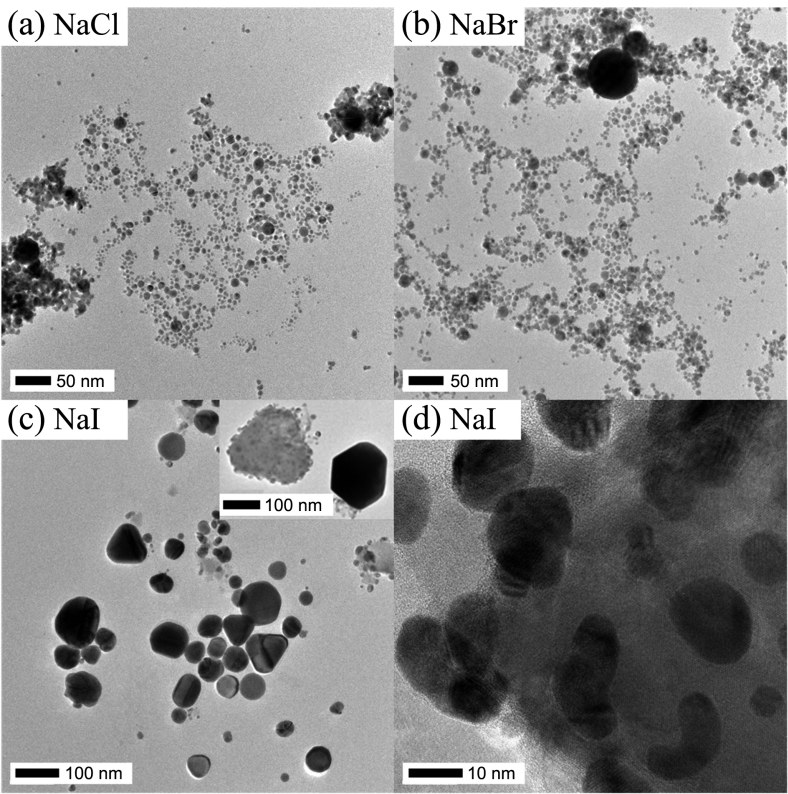

Figure 2. FE-TEM images of AuNPs synthesized in (a) $\mathrm{NaCl}$, (b) $\mathrm{NaBr}$, (c) and (d) NaI solutions by the Method I. 

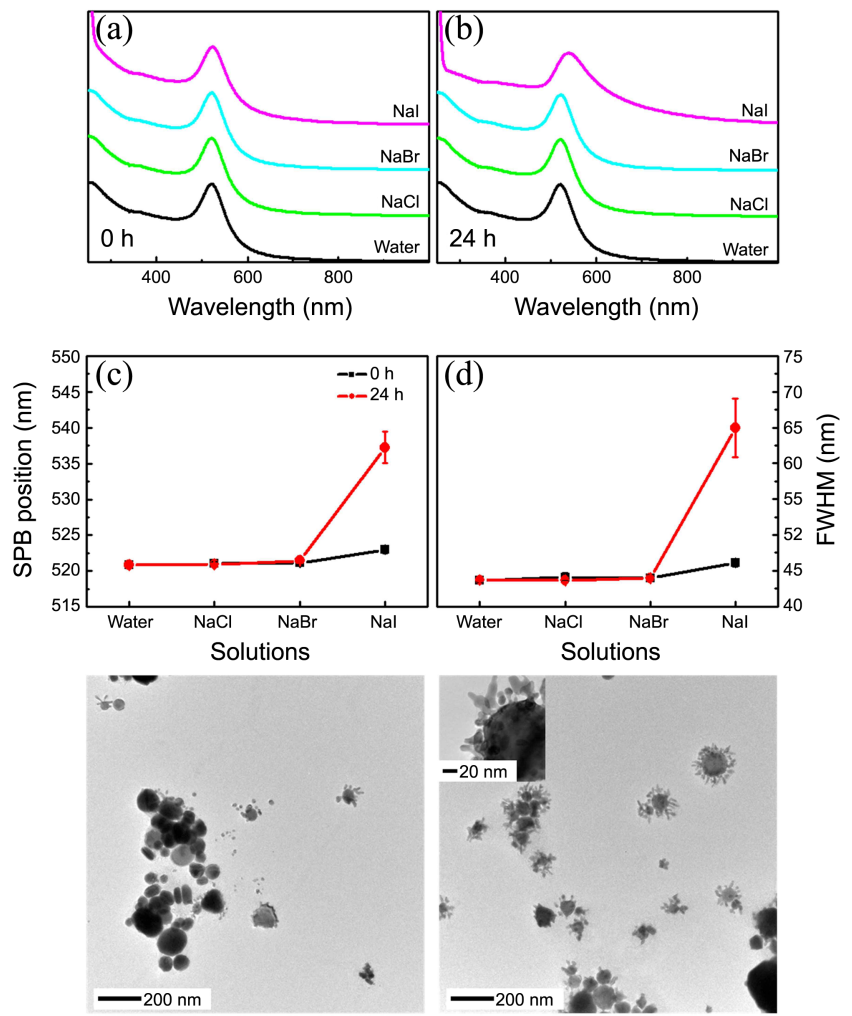

Figure 3. UV-Vis spectra of AuNPs prepared by the Method II (a) right after synthesis $(0 \mathrm{~h})$, (b) after $24 \mathrm{~h}$; (c) the shift of the surface plasmon band peak position for various electrolyte solutions, (d) the change of the FWHM for various electrolyte solutions, (e) and (f) FE-TEM images of AuNPs in NaI solution after $24 \mathrm{~h}$.

Method II: Addition of Electrolyte Solution to AuNPs Solution Prepared in Deionized Water. Halide ions in solution have influence on the stability of colloids during the storage as well as on the synthesis of NPs by LAL. To examine the effects of ions on the stability of gold nanoparticles in colloid, halide ions were added to AuNPs solution that had been prepared in deionized water, giving final concentration of halide ions of $7 \mathrm{mM}$. As displayed in Figures 3(a)(d), there were no practical changes in NP colloids when applied with chloride and bromide ions. However, right after adding NaI solution into AuNPs colloid, the SPB peak position was red shifted as much as $2 \mathrm{~nm}$, and the FWHM increased more than $2 \mathrm{~nm}$, which is similar to the results of the Method I shown in Figure 1; the SPB peak position shifted as much as $14 \mathrm{~nm}$ and FWHM also increased over more than $18 \mathrm{~nm}$ after $24 \mathrm{~h}$. In addition, the absorbance at the interband transition region decreased noticeably while the absorbance at IR region increased drastically, which indicates the aggregation of NPs as observed in the Method I. In the Method II, however, big triangular nanoplates were not observed. Instead, small NPs were found attached on the surface of big NPs like a sunflower as shown in the inset of Figures 3(e) and 3(f).

Comparison of the Two Methods: We compared the aggregation process of NPs in the two different processes for $24 \mathrm{~h}$ as shown in Figure 4: laser ablation of the Au target in

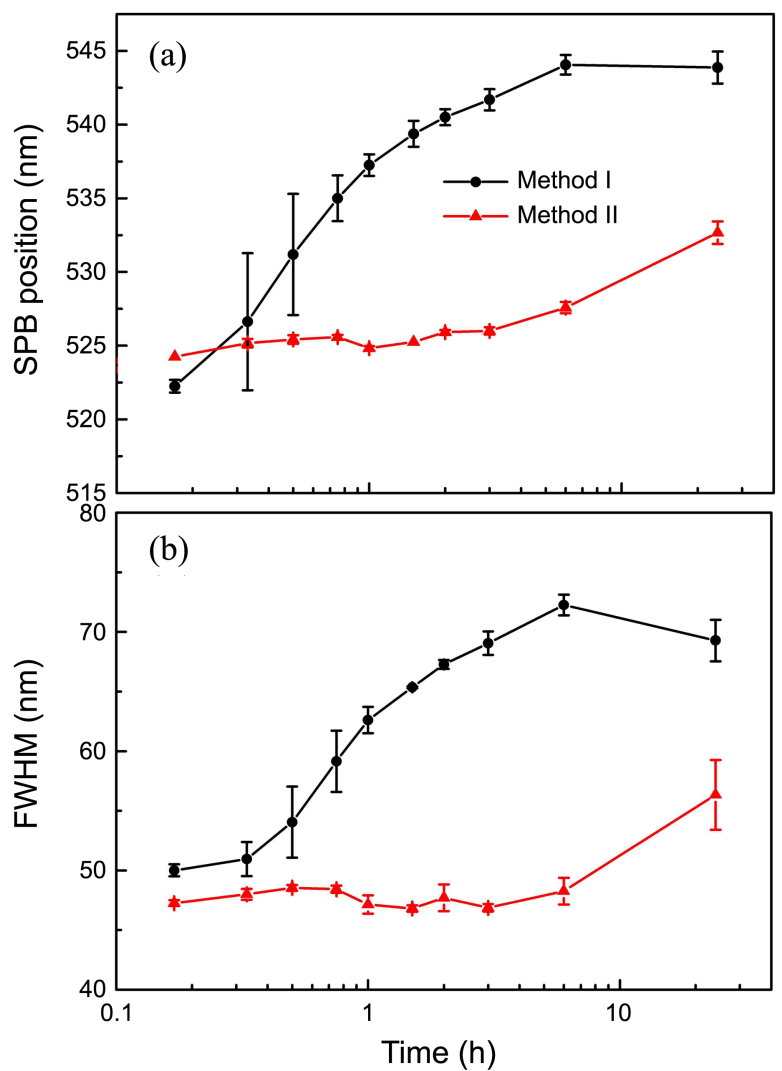

Figure 4. The time-dependent changes of (a) the peak position of the surface plasmon band and (b) FWHM for AuNPs solutions prepared by Method I, Method II.

$\mathrm{NaI}$ solution (the Method I) and adding NaI solution to the prepared AuNPs solution (the Method II). In case of the Method I, the SPB peak position shifted toward the longer wavelength and the FWHM increased gradually until $6 \mathrm{~h}$ after. The changes with time reached a plateau after $6 \mathrm{~h}$ and both SPB peak wavelength and FWHM decreased a little after $6 \mathrm{~h}$ due to formation of big NPs by aggregation. The growth of NPs with time was clear as shown by the TEM images in Figure 5. The average diameters of AuNPs were 20, 50, and $100 \mathrm{~nm}$ after $1 \mathrm{~h}, 3 \mathrm{~h}$, and $6 \mathrm{~h}$, respectively. The color of AuNPs colloid turned murky magenta from clear wine red and it changed gradually after $24 \mathrm{~h}$ to clear pale pink violet. This implies that NPs have grown progressively to certain size over $6 \mathrm{~h}$ and larger particles formed thereafter may sink down, which was visible inside the sample vial. Among various cations and anions, only iodide ions have apparent influence on the formation and aggregation of gold nanoparticles during and after laser ablation. It is intriguing that triangular and hexagonal nanoplates with sharp edge were formed when the gold target was irradiated in the presence of iodide ion (the Method I) while they were missing in the Method II. Also, when we adopted the Method II, the changes in the SPB peak position and the FWHM over the time were negligible until $3 \mathrm{~h}$ as shown in Figure 4. The aggregation was accelerated after $3 \mathrm{~h}$, which indicates that big NPs were formed by aggregation of small NPs due to the increased van der Waals interaction by iodide ions attached 


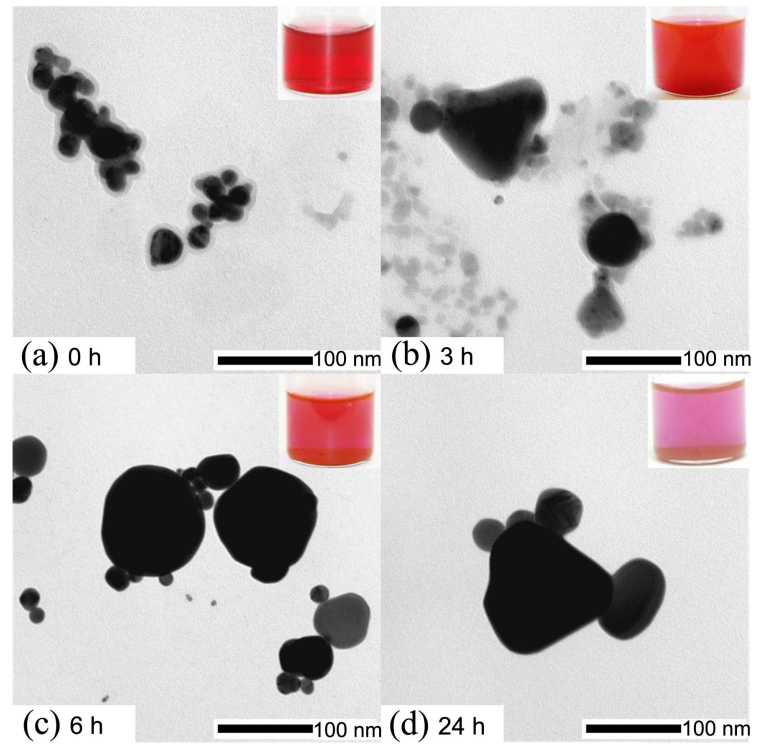

Figure 5. The EF-TEM images of AuNPs prepared by the Method I (a) right after synthesis $(0 \mathrm{~h})$, (b) after $3 \mathrm{~h}$, (c) after $6 \mathrm{~h}$, (d) after $24 \mathrm{~h}$. The insets show the change in the color of AuNPs solutions with time.

to AuNPs. It is of note that big AuNPs prepared by the Method I and II are different; triangular nanoplate with small NPs attached and sunflower-like big NPs, respectively. Comparing the two Methods, we conclude that the presence of iodide ions in solution provokes aggregation of NPs and, furthermore, LAL in iodide solution triggers certain photochemical phenomena on the surface of NPs to produce triangular nanoplates. This will be discussed in the following section.

\section{Discussion}

From our results shown above, it is clear that the size and stability of NPs strongly depend on the property of ions in solution; in particular, anions influence the surface properties of metal nanoparticles. ${ }^{48,49}$ In LAL, nucleation of atoms begins to produce seeds or atomic clusters in the initial stage and subsequently the seeds grow to NPs by calescence. ${ }^{29}$ The initial formation of seeds occurs in a very short time scale during the cooling of the plasma plume, ${ }^{29}$ and therefore it is difficult to imagine that ambient ions in the solution play a significant role during the initial stage of nucleation. ${ }^{50}$ After the nucleation process, halide ions are expected to be involved in the growth of NPs affecting the growth and coalescence of them, which actually govern their size, shape, and stability. ${ }^{29}$

General Mechanisms to Explain the Increased Stability of NPs Produced by LAL. In LAL, NPs are exposed to high temperature and pressure environment invoked by lasertarget interaction, where the surface of AuNPs may well be partially oxidized in aqueous solution. ${ }^{42,50,51}$ Subsequently, the reaction between $\mathrm{Au}-\mathrm{O}-\mathrm{Au}$ on the surface and $\mathrm{OH}^{-}$ions in aqueous solution brings about Au- $\mathrm{O}^{-}$on the surface of AuNPs, which is believed to be responsible to the increased stability of NPs prepared by LAL compared by chemical reduction; electronic repulsion between negatively charged NPs hinders further aggregation of NPs. Therefore, the average size of AuNPs that were synthesized in base solution is smaller than in acid solution or water. ${ }^{42,44,50}$ In the presence of halide ions, halide ions also attack Au-O-Au to give $\mathrm{Au}-$ $\mathrm{O}^{-}$and $\mathrm{Au}-\mathrm{X}$ on the surface of AuNPs and the increased surface charge help reduce the size as reported by Bae et $a .^{43}$

What Happens in Iodide Solution? Iodide ions in solution did not show any size reducing effect for AuNPs unlike chloride and bromide ions as displayed in Figure 2. They rather induced aggregation of NPs after synthesis. Therefore, we need different viewpoints for iodide solution from the above general mechanisms of LAL. We can consider the effects of halide ions on the size of NPs as follows: the affinity of halide ions to the gold surface $e^{50}$ and the degree of surface-to-adsorbate charge transfer. ${ }^{50,52-54}$

The adsorption rate of halide ions on the surface of AuNPs is determined by the affinity of halide ions to gold which is in order $\mathrm{Cl}^{-}<\mathrm{Br}^{-}<\mathrm{I}^{-}, 46,53,56-58$ The stability of Au and halide ion bond also follows the same order, $\mathrm{Cl}^{-}<\mathrm{Br}^{-}<\mathrm{I}^{-53}$. Also, the degree of surface-to-adsorbate charge transfer among the halide ions, which is $\mathrm{Cl}^{-}<\mathrm{Br}^{-}<\mathrm{I}^{-54,55}$ This is in line with our experimental results; the average sizes of AuNPs synthesized in the presence of chloride, bromide, and iodide ions (the Method I) were $5.3 \pm 2.7 \mathrm{~nm}, 7.0 \pm 4.6 \mathrm{~nm}$, and $41.6 \pm$ $38.9 \mathrm{~nm}$, respectively. Since AuNPs produced by LAL are positively charged due to photoionization, they can be stabilized and, furthermore, avoid Coulomb explosion when negative charge is transferred from the adsorbed halide ion on the surface of AuNPs. It is of note that the recombination of solvated photoelectrons with positively charged AuNPs compete with the adsorption of halide ions. Yamada et al. reported that the charge state of AuNPs increased with the increase in the concentration of sulfur dodecyl sulfate (SDS) until it reached to a critical micelle concentration by interrupting recombination of ejected electrons, and the size of NPs decreased with the increase of charge state due to Coulomb explosion. ${ }^{52,59,60}$ Although the degree of surfaceto-adsorbate charge transfer does not play a central role in the determination of the average size of NPs, it may be, at least, partially responsible for the resultant size of NPs.

Formation Mechanisms of Triangular Nanoplates in the Method I. Iodide ions have been widely used to help synthesize triangular nanoplates in chemical reduction method. ${ }^{46,47}$ Millstone et al. proved their critical role as they detected iodine only on the triangular nanoplates using XPS, but not on the rod- or spherical-shaped NPs. ${ }^{47}$ Tsuji et al. suggested that $\mathrm{Ag}_{\mathrm{n}-1}{ }^{-}$and $\mathrm{AgI}_{2}{ }^{-}$ions were produced in the etching process of spherical AgNPs, which reformed into nanoprisms or nanorods by the photoreduction into $\mathrm{Ag}_{\mathrm{n}}{ }^{61}$; during photoirradiation, plasmon excitation induced electronic field on the surface of $\mathrm{NPs}^{46,61}$ and $\mathrm{Ag}$ atoms accumulated on the specific facet of (100) and (110) to form anisotropic structures.

In our experiment, it also turned out that photoirradiation 

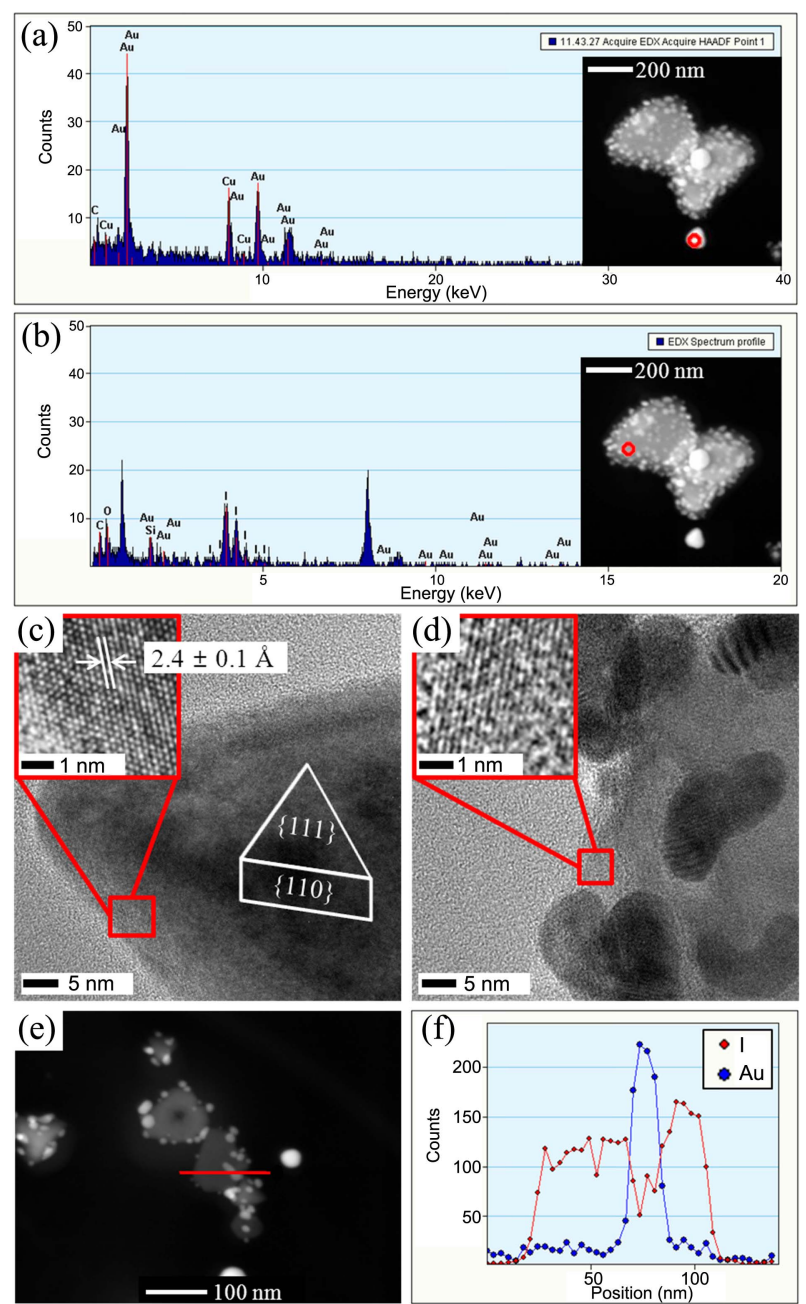

Figure 6. (a) The EDX spectrum for a small triangular $\mathrm{Au}$ nanoplate (marked as red circle), (b) The EDX spectrum for a large triangular Au nanoplate with small NPs attached (marked as red circle), (c) The HR-TEM image of a small triangular $\mathrm{Au}$ nanoplate, (d) The HR-TEM image of a large triangular $\mathrm{Au}$ nanoplate, (e) The EDX line analysis for a large triangular $\mathrm{Au}$ nanoplate, (f) The EDX line profile of $\mathrm{Au}$ and I for a triangular $\mathrm{Au}$ nanoplate shown in (e).

triggered the production of crystalline $\mathrm{NPs}^{53,61-63}$ when LAL was performed in iodide solution; triangular and hexagonal nanoplates were produced by the Method I as observed by Tsuji et al.$^{61}$ On the other hand, in case of the Method II, just modified (or rounded) triangular NPs and sunflower-like aggregates of AuNPs with small NPs attached on the surface of a big NP were observed as shown in Figures 3(e)-(f).

Laser ablation of $\mathrm{Au}$ target in iodide solution induces the growth of triangular and hexagonal plates by controlling the direction in the growth of AuNPs. ${ }^{46,61}$ The EDX and TEM analysis of a small triangular plate and a large triangular plate with small NPs are shown in Figures 2(c), 2(d) and 6; the small plate turned out to be gold as no iodine was detected (Fig. 6(a)), while iodine peaks were dominant for the large plate (Fig. 6(b)). Figure 6(b) shows a large triangular plate with many small NPs adsorbed on the surface, which was also shown in the Figure 2(d). For the small plate, the distance between the neighboring atom columns was 2.4 $\pm 0.2 \AA$, the pit depth of $\mathrm{Au}$ (111), which manifests that photoirradiation induced accumulation of reduced $\mathrm{Au}_{n}$ preferably on (110) and (100) facets to form nanoplates with (111) face as shown in Figure 6(c). The density of triangular nanoplates were not high due to the short irradiation time in the Method I. ${ }^{62}$ In case of the larger plate, the crystallinity was relatively poor as shown in Figure 6(d) presumably because the surface was covered by iodine; as illustrated in Figures 6(e) and 6(f), the small NPs attached to the large triangular plate are AuNPs but the surface of the large plate consisted mostly of iodine.

Iodide ions are easily adsorbed on $\mathrm{Au}$ (111) than other facets such as (110) and (100). ${ }^{47,56,57}$ Besides, excess iodide ions are able to change triangular and hexagonal plates into plates with irregular edges due to its strong affinity to $\mathrm{Au}$ (111). ${ }^{53,57}$ Rai et al. found that the nanoprisms were reconstructed into such plates at $24 \mathrm{~h}$ after adding iodide ions ${ }^{56}$; iodide ions form hexagonal packed adlayer which is mismatched with the Au (111) lattice plane. ${ }^{53,56}$ The mismatch brings interfacial strain on the surface, and the strain is relieved by transforming the surface of gold triangular plates to corrugated edges. ${ }^{56}$ Such AuNPs with irregular edges were also observed in our experiment as shown in Figure 2(c). To conclude, iodide ions stimulate the growth of triangular $\mathrm{Au}$ nanoplates because they work as stronger etchant than other halide ions, ${ }^{61}$ but they eventually contribute to the formation of irregular-edged plates due to the strong affinity to $\mathrm{Au}(111)$.

\section{Conclusion}

We have investigated the effects of ions on the formation of AuNPs by LAL by two different methods: laser ablation of $\mathrm{Au}$ target in various electrolyte solutions $(7 \mathrm{mM}$ of $\mathrm{LiCl}$, $\mathrm{NaCl}, \mathrm{KCl}, \mathrm{NaBr}$, and $\mathrm{NaI}$ ) and mixing of AuNPs solution prepared in deionized water by LAL with each electrolyte solution. Only in the Methods I, chloride and bromide ions in solution helped decrease the average size of AuNPs compared to that prepared in deionized water, while iodide ions triggered aggregation of NPs due to large van der Waals interaction. On the other hand, the dependence of AuNP size on the cations $\left(\mathrm{Li}^{+}, \mathrm{Na}^{+}, \mathrm{K}^{+}\right)$was negligible. When Au target was irradiated in iodide solution, $\mathrm{Au}$ triangular nanoplates were formed due to high affinity of iodide ion on $\mathrm{Au}$ (111) surface and subsequent photoreduction to produce $\mathrm{Au}$ clusters.

Acknowledgments. This research was supported by the Basic Science Research Program through the National Research Foundation of Korea (NRF) funded by the Ministry of Education, Science, and Technology (2012R1A1A2001960).

\section{References}

1. Kelly, K. L.; Coronado, E.; Zhao, L. L.; Schatz, G. C. J. Phys. Chem. B 2003, 107, 668. 
2. Schmid, G.; Simon, U. Chem. Commun. 2005, 6, 697.

3. Hori, H.; Teranishi, T.; Nakae, Y.; Seino, Y.; Miyake, M.; Yamada, S. Phys. Lett. A 1999, 263, 406.

4. Huang, D.; Liao, F.; Molesa, S.; Redinger, D.; Subramanian, V. J. Electrochem. Soc. 2003, 150, G412.

5. Lee, H.; Kim, A.; Ahn, I. S.; Joo, S.-W.; Lee, S. Y.; Yoon, K.-A.; Lee, K. Chem. Commun. 2011, 47, 11477.

6. Selid, P. D.; Xu, H.; Collins, E. M.; Face-Collins, M. S.; Zhao, J. X. Sensors 2009, 9, 5446 .

7. Standridge, S. D.; Schatz, G. C.; Hupp, J. T. Langmuir 2009, 25, 2596.

8. Lee, H. J.; Jeong, S. H. Text. Res. J. 2005, 75, 551.

9. Koponen, I. K.; Jensen, K. A.; Schneider, T. J. Phys.: Conference Series 2009, 012048 .

10. Salata, O. V. J. Nanobiotechnol. 2004, $2,1$.

11. Zhang, Q.; Liu, F.; Nguyen, K. T.; Ma, X.; Wang, X.; Xing, B.; Zhao, Y. Adv. Funct. Mater. 2012, 22, 5144.

12. Na, H. B.; Song, I. C.; Hyeon, T. Adv. Mater. 2009, 21, 2133.

13. Day, E. S.; Morton, J. G.; West, J. L. J. Biomech. Eng. 2009, 131, 0740011 .

14. Mustafa, D. E.; Yang, T.; Xuan, Z.; Chen, S.; Tu, H.; Zhang, A. Plasmonics 2010, 5, 221.

15. Pan, Y.; Neuss, S.; Leifert, A.; Fischler, M.; Wen, F.; Simon, U.; Schmid, G.; Brandau, W.; Jahnen-Dechent, W. Small 2007, 3, 1941.

16. Bar-Ilan, O.; Albrecht, R. M.; Fako, V. E.; Furgeson, D. Y. Small 2009, 5, 1897.

17. Hong, J.-S.; Kim, S.; Lee, S. H.; Jo, E.; Lee, B.; Yoon, J.; Eom, I.C.; Kim, H.-M.; Kim, P.; Choi, K.; Lee, M. Y.; Seo, Y.-R.; Kim, Y.; Lee, Y.; Choi, J.; Park, K. Nanotoxicology 2013 Early Online, 1 .

18. Lee, K.-S.; El-Sayed, M. A. J. Phys. Chem. B 2006, 110, 19220.

19. Link, S.; El-Sayed, M. A. J. Phys. Chem. B 1999, 103, 4212.

20. Prochazka, M.; Stepanek, J.; Vlckova, B.; Srnova, I.; Maly, P. J. Mol. Struct. 1997, 410-411, 213.

21. Lal, S.; Grady, N. K.; Kundu, J.; Levin, C. S.; Lassiter, J. B.; Halas, N. J. Chem. Soc. Rev. 2008, 37, 898.

22. Prochazka, M.; Mojzes, P.; Stepanek, J.; Vlckova, B.; Turpin, P.Y. Anal. Chem. 1997, 69, 5103.

23. Srnova, I.; Prochazka, M.; Vlckova, B.; Stepanek, J.; Maly, P. Langmuir 1998, 14, 4666.

24. Heo, D. N.; Yang, D. H.; Moon, H.-J.; Lee, J. B.; Bae, M. S.; Lee, S. C.; Lee, W. J.; Sun, I.-C.; Kwon, I. K. Biomaterials 2012, 33, 856.

25. Lammers, T.; Aime, S.; Hennink, W. E.; Storm, G.; Kiessling, F. Acc. Chem. Res. 2011, 44, 1029.

26. Xiao, J.; Qi, L. Nanoscale 2011, 3, 1383.

27. Murphy, C. J.; Sau, T. K.; Gole, A. M.; Orendorff, C. J.; Gao, J.; Gou, L.; Hunyadi, S. E.; Li, T. J. Phys. Chem. B 2005, 109, 13857.

28. Alkilany, A. M.; Nagaria, P. K.; Hexel, C. R.; Shaw, T. J.; Murphy, C. J.; Wyatt, M. D. Small 2009, 5, 701.

29. Amendola, V.; Meneghetti, M. Phys. Chem. Chem. Phys. 2009, 11,3805 .

30. Talukder, A. I.; Sultana, P.; Haider, A. F. M. Y.; Wahadoszamen, M.; Abedin, K. M.; Farhad, S. F. U. Eur. Phys. J. D 2010, 60, 295.

31. Kim, T.; Lee, K.; Gong, M.; Joo, S.-W. Langmuir 2005, 21 , 9524.

32. Darroudi, M.; Ahmad, M. B.; Zamiri, R.; Abdullah, A. H.; Ibrahim, N. A.; Shameli, K.; Husin, M. S. J. Alloys Compd. 2011, $509,1301$.

33. Brito-Silva, A. M.; Gomez, L. A.; de Araujo, C. B.; Galembeck,
A. J. Nanomater 2010, 142897.

34. Tsuji, T.; Iryo, K.; Watanabe, N.; Tsuji, M. Appl. Surf. Sci. 2002 202,80 .

35. Mafune, F.; Kohno, J.; Takeda, Y.; Kondow, T. J. Phys. Chem. B 2000, 104, 8333.

36. Chen, Y.-H.; Yeh, C.-S. Colloids Surf. A 2002, 197, 133.

37. Mafune, F.; Kondow, T. Chem. Phys. Lett. 2003, 372, 199.

38. Sylvestre, J.-P.; Kabashin, A. V.; Sacher, E.; Meunier, M.; Luong, J. H. T. J. Am. Chem. Soc. 2004, 126, 7176.

39. Zamiri, R.; Azmi, B. Z.; Naseri, M. G.; Ahangar, H. A.; Darroudi, M.; Nazarpour, F. K. Appl. Phys. A 2011, 105, 255.

40. Balasubramanian, R.; Xu, J.; Kim, B.; Sadtler, B.; Wei, A. $J$. Dispersion Sci. Technol. 2001, 22, 485.

41. Tilaki, R. M.; Irajizad, A.; Mahdavi, S. M. Appl. Phys. A 2006, 84, 215.

42. Sylvestre, J.-P.; Poulin, S.; Kabashin, A. V.; Sacher, E.; Meunier, M.; Luong, J. H. T. J. Phys. Chem. B 2004, 108, 16864.

43. Bae, C. H.; Nam, S. H.; Park, S. M. Appl. Surf. Sci. 2002, 197, 628.

44. Siskova, K.; Vlckova, B.; Turpin, P. Y.; Fayet, C. J. Phys. Chem. $C$ 2008, 112, 4435 .

45. Amendola, V.; Meneghetti, M. J. Phys. Chem. C 2009, 113, 4277.

46. Ha, T. H.; Koo, H.-J.; Chung, B. H. J. Phys. Chem. C 2007, 111, 1123.

47. Millstone, J. E.; Wei, W.; Jones, M. R.; Yoo, H.; Mirkin, C. A. Nano Lett. 2008, 8, 2526.

48. Filankembo, A.; Giorgio, S.; Lisiecki, I.; Pileni, M. P. J. Phys. Chem. B 2003, 107, 7492 .

49. Filankembo, A.; Pileni, M. P. J. Phys. Chem. B 2000, 104, 5865.

50. Rehbock, C.; Merk, V.; Gamrad, L; Streubel, R.; Barcikowski, S. Phys. Chem. Chem. Phys. 2013, 15, 3057.

51. Muto, H.; Yamada, K.; Miyajima, K.; Mafune, F. J. Phys. Chem. C 2007, 111, 17221.

52. Yamada, K.; Tokumoto, Y.; Nagata, T.; Mafune, F. J. Phys. Chem. $B$ 2006, 110, 11751

53. Maillard, M.; Huang, P.; Brus, L. Nano Lett. 2003, 3, 1611-1615.

54. Sibbald, M. S.; Chumanov, G.; Cotton, T. M. J. Phys. Chem. 1996, $100,4672-4678$

55. Gao, P.; Weaver, M. J. J. Phys. Chem. 1986, 90, 4057.

56. Rai, A.; Singh, A.; Ahmad, A.; Sastry, M. Langmuir 2006, 22, 736.

57. Magnussen, O. M. Chem. Rev. 2002, 102, 679.

58. Ignaczak, A.; Gomes, J. A. N. F. J. Electroanal. Chem. 1997, 420, 71.

59. Yamada, K.; Miyajima, K.; Mafune, F. J. Phys. Chem. C 2007, 111,11246

60. Werner, D.; Hashimoto, S.; Uwada, T. Langmuir 2010, 26, 9956.

61. Tsuji, T.; Okazaki, Y.; Tsuji, M. J. Photochem. Photobiol. A 2008, 194, 247.

62. Jin, R.; Cao, Y.; Mirkin, C. A.; Kelly, K. L.; Schatz, G. C.; Zheng, J. G. Science 2001, 294, 1901.

63. Jin, R.; Cao, Y. C.; Hao, E.; Metraux, G. S.; Schatz, G. C.; Mirkin, C. A. Nature 2003, 425, 487.

64. Glidle, A.; Yasukawa, T.; Hadyoon, C. S.; Anicet, N.; Matsue, T.; Nomura, M.; Cooper, J. M. Anal. Chem. 2003, 75, 2559.

65. Poirier, G. E. Langmuir 1997, 13, 2019.

66. Scott, M. C.; Chen, C.-C.; Mecklenburg, M.; Zhu, C.; Xu, R.; Ercius, P.; Dahmen, U.; Regan, B. C.; Miao, J. Nature 2012, 483, 444.

67. Edinger, K.; Golzhauser, A.; Demota, K.; Woll, Ch.; Grunze, M. Langmuir 1993, 9, 4. 